\title{
An empirical analysis of the influence of Guanxi on turnover intention and promotion opportunity of civil servants
}

\author{
Li Yongkang ${ }^{1}$, Ai Jun ${ }^{2}, \mathrm{Li} \mathrm{Bo} o^{3}$ \\ School of Public Finance and Management, Yunnan University of Finance and Economics, Kunming, China \\ 1.121651831@qq.com; 2.1021501054@qq.com; 3.775446475@qq.com
}

\begin{abstract}
Based on a sample of 405 Yunnan civil servants, this paper constructs and verifies the model of Guanxi on turnover intention and promotion opportunities of civil servants, the main content of the study is Guanxi as independent variable, turnover intention and promotion opportunity as the dependent variable, and job satisfaction as the mediator variable, descriptive analysis and AMOS structure mediation analysis were carried out. The results of the study show that, the influence of Guanxi on job satisfaction has a only direct effect. And the influence of Guanxi on turnover intention has a direct effect(0.368) more than an indirect effect(0.140), the mediation variable of job satisfaction does not work. However, the influence of Guanxi on promotion opportunities has a direct effect(-0.088) much less than an indirect effect(-0.196), the mediation variable of job satisfaction is significant.
\end{abstract}

Keywords-Guanxi ; Turnover intention ; Promotion Opportunity; Job satisfaction; Yunnan Province Civil Servants

\section{INTRODUCTION}

The workplace relationship is based on the specific soil of Chinese culture. In essence, it is "Guanxi"(Chinese style relationship ), Whether it is an enterprise or public organization, Guanxi affect all kinds of personnel activities organized by employees. Because of the differences between Chinese and Western cultures, the connotation of the relationship has different characteristics, and the word "Guanxi" is defined by the West scholars as Chinese style relationship. "Guanxi" can also be considered as a special interpersonal relationship, which refers to the sum of various social relationships produced in the process of activities between people and people. To a certain extent, it reflects a psychological state of the individual in the process of satisfying its social needs. The generation of social people is based on the effect of interpersonal relationship, and people promote themselves through interpersonal interaction in society, and realize their own value, and people cannot do without the role of interpersonal relations. At the same time, Chinese relations can be divided into formal and informal relations, and this article is to discuss the informal relationship, which is a more common organization of interpersonal relationships. From the literal meaning of Guanxi, including the connection between individuals and social groups (Chow and Ng, 2004; Fan, 2002; Tung, 1996), these relationships are based on mutual benefit and concern (Yang, 1994).Barnard (the founder of modern management theory) and Mayo all emphasize that even in formal organizations, there are still some informal relationships.With the development of society, informal relationship has attracted more and more attention in economics, sociology, politics and management. Scholars in China, such as Yang Guoshu, Huang Guangguo, and Le Guoan, as well as foreign scholars such as Little-field, Yang and Chan, have studied Chinese relations more, and most of the related literature can be used as reference. For example, Yang (1993) emphasizes that the basis of Guanxi is mutual benefit. He is studying from the individual level, and Tsang (1998) emphasizes that Guanxi is "informal, specific" interpersonal communication. Bao Gongmin, Liu xiao scholar (2008), thinks that the existence of Guanxi in the organization will be associated with the bad phenomena such as bribery and favoritism with the advancement of time, destroying the fair principle in the organization and causing the unhealthy development of the organization. To sum up, Chinese style relations still have an important position in the Chinese cultural concept. Its influence is multifaceted, it is also the inevitable product of the development of Chinese culture. At the same time, it has the ancient and rich culture of Chinese culture. Organization and personnel activities not only play an important role in promoting, but also have significant hindrance. In this article, it mainly refers to the informal interpersonal relationship that exists in the organization, mainly including the special interpersonal atmosphere in the organization and the relationship between the upper and lower levels. To sum up, "Guanxi" is defined as the potential of organizing members to bring themselves scarce resources and avoid difficulties in the organization. It is a kind of relationship that can easily have a negative impact on the organization.

Guanxi has been widely recognized by academia as a significant influence on personnel activities in organizations. Zhang Mian (2006) in the study of IT employees found that the higher the Guanxi, the higher opportunities of getting promotion and the lower risk of being fired. Chenung (2009) pointed out that Guanxi between the upper and lower levels had a positive effect on job satisfaction. Chen and Francesco (2004) found that in various organizations, employers tend to be inclined to promote and reward employees who have good relationships with themselves, and this "relationship" is mainly a kind of Guanxi. Li Junhao (2013) points out that Guanxi operation has a negative impact on performance evaluation and job satisfaction. Zhang and Zhang (2006) points out that, in the reciprocal exchange, when the collective resources of the official organization are used by individuals, the role of Guanxi will arise. It will be associated 
with the inappropriate returns and underground transactions, damage the fairness within the organization and cause the reduction of job satisfaction and the improvement of turnover intention. Dunfee, Warren, \& Li Fan (2004) found that when Guanxi can make a person a beneficiary, it damages the collective, organizational and social interests in a wider range. Chen, Friedman etc. (2011) think that Guanxi operation will have a negative impact on organizational procedural fairness, and affect organizational job satisfaction. Zhang Xiujuan, Wang Chunben (2004) points out that Guanxi have a greater impact on employees' promotion opportunities than salary allocation, performance evaluation and employee recruitment. Zhang Mian (2006), based on the employee revision model of Price Mueller model, proposed that Guanxi as an independent variable has an effect on turnover intention. In the Price-Mueller model, job satisfaction is considered as an intermediary variable, and the independent variable affects turnover intention through the intermediary of job satisfaction.

In the civil servants organization, Guanxi is more significant. According to the interview of the topic group, it is found that Guanxi has a significant influence on the civil service system. It has both positive and negative effects. The investigation thinks that Guanxi is a more significant variable in the public service system. It has an impact on the promotion opportunities and turnover intention of civil servants. Therefore, this paper makes an empirical study on Guanxi in the civil service organization through the method of issuing the questionnaire on the spot, and analyzes the influence path and effect value of the two dependent variables on the promotion opportunity and turnover intention of the
Guanxi, and puts forward the corresponding suggestions and measures.

\section{RESEARCH MODEL AND HYPOTHESIS}

This model is inspired by the Price-Mueller model and the revised Price-Mueller (2000) model proposed by Zhang Mian on the basis of the revision of the model. It is necessary to point out that the model is a whole model of turnover theory. The independent variable of the Guanxi studied in this paper is a reference to the relational variables in the Price-Mueller (2000) model, and the study of the job satisfaction and turnover intention of the dependent variables referring to the medium variables of the model. The difference is that the promotion opportunities in the revised Price-Mueller (2000) model are independent variables, but we find that the Guanxi has a significant impact on the promotion opportunities through the collection of relevant literature at home and abroad. At the same time, the Price-Mueller model and the revised Price-Mueller (2000) model proposed by Zhang Mian on the basis of the revised model are enterprise employees. The object of this paper is civil servants in Yunnan province, the purpose of this study is to analyze the suitability of the two models to the civil service group and the verification points, and analyze the relationship between these variables in the civil service organization. Based on the variables considered by the special profession, by reference to the Price-Mueller (2000) model and the literature collection, a model of the influence of Guanxi on the turnover intention and promotion opportunity of civil servants is established, as shown in Figure 1

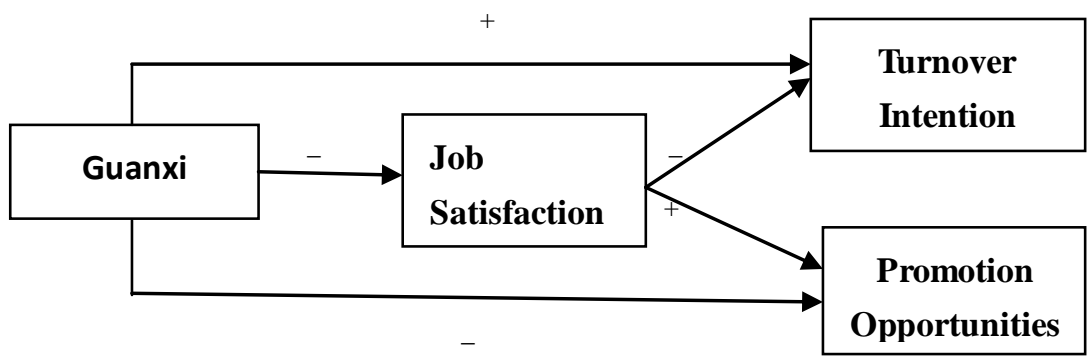

Fig. 1 a model of the influence of Guanxi on turnover intention and promotion opportunity of civil servants

Based on the model of the influence of Guanxi on turnover intention and promotion opportunity of civil servants, the following research hypotheses are proposed.

H1: Guanxi directly affects turnover intention and has a significant positive effect.

H2: Guanxi directly affect promotion opportunities and have a significant negative effect.

\section{DATA AND METHOD}

\section{A. Data}

The questionnaire survey adopts the method of random sampling. The location of the survey includes Kunming city, Mangshi of Dehong and Malipo County of Wenshan in Yunnan Province. The samples include developed regions(Kunming) of Yunnan Province, and also include relatively backward areas(Wenshan), and the geographical location also has strong representativeness. Through inquiring the relevant information, it is found that there are obvious regional differences in the treatment of civil servants, and a
H3: Guanxi directly affects job satisfaction and has a significant negative effect.

H4: Guanxi indirectly affects turnover intention through job satisfaction and has a significant positive effect.

H5: Guanxi indirectly affects promotion opportunities through job satisfaction and has a significant negative effect.

preliminary understanding of the situation of the civil service group in Yunnan is based on the large data analysis. At the same time, according to the Price-Mueller model corresponding scale analysis and modification, and based on this as the basis for the quality of life of civil servants in Yunnan province questionnaire. At the end of the deadline, 553 questionnaires were issued in the three regions of Kunming, Manshi and Malipo County, of which 148 is invalid, and the final effective questionnaire are 405, which basically reached the number of samples required for the study. The survey samples are basically in line with the number of samples required by the empirical research, and the civil servants in these three areas are selected for questionnaire distribution. In the geographical location, they include the 
Middle East, South and western regions of Yunnan province. To a certain extent, it represents the public servants of the whole Province of Yunnan.

The basic distribution of demographic information in the survey sample is as follows:

1) In the proportion of sex data, men account for $51.4 \%$, and the proportion of women is $42.2 \%$. It can be seen that the proportion of men and women in the civil service system in Yunnan is relatively balanced, although male civil servants are more than women civil servants,But by observing Professor Zhang Mian's survey of employee turnover intention of IT employees, it is found that the sex ratio of men and women in IT enterprises is different, the proportion of men is greater than that of women, and the difference is $30.2 \%$. There is a larger proportion of male to female in the civil service system and market companies, the difference is that there is relatively little discrimination against women in the civil service system.

2) from the national distribution, the number of civil servants belonging to the Han nationality in Yunnan province is 227, and there are 151 people belonging to ethnic minorities, of which the proportion of ethnic minorities is up to $37.3 \%$, which is far higher than the proportion of the civil service groups in other provinces. The reason why we should consider the national variable is that Yunnan province belongs to a multi ethnic group, and in the actual investigation, it is found that the civil service group of ethnic minorities is more stable than the Han civil servant group. Therefore, in order to further discuss the national variation in the whole Yunnan civil service group, the ethnic change is more deeply discussed. We have chosen the national variable as a feature.

3) The education level of the civil service team is mainly concentrated on the undergraduate level, of which the degree of high school education is $2.2 \%$, the degree of college education is $27.7 \%$, the degree of undergraduate education is $64.9 \%$, and the degree of education of master and above is $4.4 \%$,From this, we can see that the educational level of the civil service in Yunnan province has been greatly improved after years of public recruitment. Most of the talent sources of the civil service system in Yunnan province are concentrated in college and undergraduate, and there are also the choice of the students who have graduated in the civil service, although the proportion is not high,but it is also public., the staff team provides a high-quality source of talent.

\section{B. Measure}

The variables and questions in this paper are designed by referring to the results of the revision of Price-Mueller (2000) and Zhang Mian (2006) according to the Chinese situation (see Table 1). It is a part of the questionnaire of "civil service quality of life questionnaire" by Li Yongkang. The serial number corresponding to the measurement item is also the corresponding serial number in the questionnaire. The source of the measurement scale is marked in Table 1. Job satisfaction was used as the mediator variable, and Guanxi as the independent variable, turnover intention and promotion opportunity as the dependent variables. The variables in the Table 1 is corresponding to the variables selected by our topic in the questionnaire. corresponding to the variables selected by our topic in the questionnaire. It is not difficult to find that there is a reverse score question in the corresponding problems of each variable, so when we enter the data, we carry on the reverse recording of the corresponding problems ( $\mathrm{R}$ represents the reverse score), and finally enter the data analysis in the SPSS.The below statistical analysis is based on this basis, so there is no longer any redundancy.

TABLE 1 MEASURING TOOLS FOR STUDYING VARIABLES

\begin{tabular}{|c|c|c|c|}
\hline $\begin{array}{c}\text { Variable } \\
\text { classification }\end{array}$ & $\begin{array}{l}\text { Variable } \\
\text { heading }\end{array}$ & Measurement items & Meter source \\
\hline \multirow{3}{*}{$\begin{array}{l}\text { Independent } \\
\text { variable }\end{array}$} & \multirow{3}{*}{ Guanxi } & $\begin{array}{l}\text { E. Through my personal relationship, I can do many things } \\
\text { that my colleagues at the same level cannot do in this unit. }\end{array}$ & \multirow{3}{*}{ Zhang mian, 2006} \\
\hline & & $\begin{array}{l}\text { F. For some important decisions of the organization, I can } \\
\text { learn more than most of my peers before releasing it. }\end{array}$ & \\
\hline & & $\begin{array}{l}\text { G. When I am in trouble at the unit, I can improve my } \\
\text { situation through my personal relationship. }\end{array}$ & \\
\hline \multirow{4}{*}{$\begin{array}{l}\text { Mediating } \\
\text { variables }\end{array}$} & \multirow[t]{4}{*}{ Job Satisfaction } & A. I am very satisfied with the current job. & \multirow{4}{*}{ Brayfield-Rothe, 1951} \\
\hline & & B. (R) My job is quite boring. & \\
\hline & & C. I found a real pleasure at work. & \\
\hline & & D. (R) I often get tired of my job. & \\
\hline \multirow{7}{*}{$\begin{array}{l}\text { Dependent } \\
\text { variable }\end{array}$} & \multirow{3}{*}{$\begin{array}{l}\text { Promotion } \\
\text { opportunities }\end{array}$} & D.In our unit, employees have a good chance of promotion. & \multirow{3}{*}{ Kim et al., 1996} \\
\hline & & E. (R) Internal promotions are rare in our organization. & \\
\hline & & $\begin{array}{l}\text { F. ( R)I don't have a chance to be promoted in my organization } \\
\text { anymore. }\end{array}$ & \\
\hline & \multirow{4}{*}{$\begin{array}{l}\text { Turnover } \\
\text { Intention }\end{array}$} & J. I want to leave the current organization. & \multirow{4}{*}{ Kim et al., 1996} \\
\hline & & $\begin{array}{l}\text { K. (R) I plan to stay in the current organization for as long as } \\
\text { possible. }\end{array}$ & \\
\hline & & $\begin{array}{l}\text { L. (R) Under normal circumstances, I will not take the } \\
\text { initiative to leave the current organization. }\end{array}$ & \\
\hline & & M. If I stay in this unit, my outlook may not be better. & \\
\hline
\end{tabular}




\section{Reliability and validity}

1) The reliability of research variables

When the reliability of the variable is analyzed, the internal consistency coefficient is generally adopted, that is, the alpha coefficient. Generally, it is believed that the alpha coefficient has a good reliability reliability when it is more than 0.7.We calculate the internal consistency coefficient alpha by using the reliability analysis function in the SPSS data analysis software to get the results, in the table 2 , the source of the scale has been marked out. Overall, the reliability coefficients of the variables studied are all above 0.7 , so they have good reliability and reliability (see Table 2).

\section{2) The structural validity of the variables}

In the analysis of reliability and validity, we selected the scale compiled by Zhang Mian, but because the object he studied was IT employees, which are different from the government civil servants, and finally got the validity and validity of the previous table. To sum up, through the reliability and validity test, we found that the selected observation variables have good reliability and validity, which has a good basis and foundation for the analysis of the following data.

\section{FINDINGS}

\section{A. Model fitting}

According to the measurement index of the influence of
The validity measurement mainly includes three aspects of the validity, the criterion validity, the content validity and the structure validity. This paper uses the structural validity test, which is to verify the validity results through the standardized factor load of the observed variables involved.Normally, as long as the significant level of each

observation variable is less than 0.01 , and the normalized factor load is higher than 0.50 , it can be considered that the observed variable has a better structural validity. Through the validity test of the following table, it is found that the measured values of the selected variables are basically consistent with the requirements, so it is considered that the measured items of the selected variables have good validity, as shown in Table 3.)。

Guanxi on turnover intention and promotion opportunity of civil servants, we first estimate the fitting degree of the influence of Guanxi on the turnover intention and promotion opportunity of civil servants, and the results are shown in the table 4. The Chi-square/df Ratio of the model of the influence of the Guanxi on civil servant turnover intentions and promotion opportunities is (Chi-square/df Ratio) 3.754 RMSEA $=0.083$. By measuring the relative fitting index, it was found that $\mathrm{CFI}=0.855<0.9, \quad \mathrm{NFI}=0.814<0.9$, and IFI $=0.857<0.9$. The model fitting coefficient is not good, so the model needs to be adjusted. Through the adjustment and revision of the model of the impact of the Guanxi on civil servant turnover intentions and promotion opportunities, a

TABLE 2 RELIABILITY RESULTS SCALE

\begin{tabular}{l|c|c|l}
\hline \multicolumn{1}{c|}{ variable } & Number of items & Alpha coefficient & \multicolumn{1}{c}{ Meter source } \\
\hline Job Satisfaction & 4 & 0.837 & Brayfield Rothe, 1951 \\
\hline Turnover Intention & 4 & 0.754 & Kim et al., 1996 \\
\hline Promotion opportunities & 3 & 0.739 & Kim et al., 1996 \\
\hline Guanxi & 3 & 0.737 & Zhang mian, 2006 \\
\hline
\end{tabular}

TABLE 3 RESULTS OF VALIDITY TEST OF CIVIL SERVANTS TURNOVER INTENTION QUESTIONNAIRE

\begin{tabular}{c|c|c|c}
\hline Latent variable & Measurement item & Normalization coefficient & Tvalue \\
\hline \multirow{3}{*}{ Turnover Intention } & 1 & 0.627 & - \\
\cline { 2 - 4 } & 2 & 0.728 & $21.479^{* * *}$ \\
\cline { 2 - 4 } & 3 & 0.699 & $20.009^{* * *}$ \\
\cline { 2 - 4 } & 4 & 0.539 & $17.826^{* * *}$ \\
\hline \multirow{4}{*}{ Job Satisfaction } & 1 & 0.792 & - \\
\cline { 2 - 4 } & 2 & 0.604 & $34.632^{* * *}$ \\
\cline { 2 - 4 } & 3 & 0.847 & $28.519^{* * * *}$ \\
\hline \multirow{2}{*}{ Promotion opportunities } & 4 & 0.734 & - \\
\cline { 2 - 4 } & 1 & 0.705 & $25.857^{* * *}$ \\
\cline { 2 - 4 } & 2 & 0.782 & $21.182^{* * *}$ \\
\hline \multirow{2}{*}{ Guanxi } & 3 & 0.626 & - \\
\cline { 2 - 4 } & 1 & 0.552 & $8.992^{* * *}$ \\
\cline { 2 - 4 } & 2 & 0.847 & $9.617^{* * *}$ \\
\hline
\end{tabular}

*** represents significant at the 0.001 level. 
model of Guanxi was created to influence civil servant turnover intentions and promotion opportunities. The model fitting coefficient is shown in Table 4 below. Chi-square/df Ratio is $1.277<3, \mathrm{p}=0.076>0.05$, RMSEA $=0.026<0.1$, $\mathrm{CFI}=0.988>0.9$, NFI $=0.949>0.9$, and $\mathrm{IFI}=0.989>0.9$. The revised model has a perfect fitting coefficient.

Through the model fitting coefficients in table 4, we can see that the revised model has a better fit, which provides a good data basis for our next mediating effect, and also proves the revised Guanxi through confirmatory exploration. The impact of the relationship on civil servants promotion opportunities and turnover intentions provides strong persuasiveness throughout the article and data analysis.

\section{B.An Analysis of the Influence of the Relationship of Guanxi on Turnover intentions and Promotion Opportunity}

Through the relationship between the various variables in the model in the AMOS to build the path structure diagram, and then conduct the corresponding data analysis, and finally get the data shown in the following table. The following table mainly analyzes the direct, indirect, and overall effects of the mediation analysis of the model of the influence of Guanxi on civil servant turnover intentions and promotion opportunities.

TABLE 4 FitTING RESUlts OF GUANXI MODEL

\begin{tabular}{|c|c|c|c|}
\hline \multirow[t]{2}{*}{ Fit statistics } & \multicolumn{2}{|c|}{ Model fitting value } & \multirow[t]{2}{*}{ Reference value } \\
\hline & Before correction & After correction & \\
\hline$\chi^{2}$ & $270.184(\mathrm{p}=0.000)$ & $74.051(\mathrm{p}=0.076)$ & $\mathrm{p}>0.05$ \\
\hline Chi-square/df & 3.754 & 1.277 & $\leqslant 3$ \\
\hline CFI & 0.855 & 0.988 & $\geq 0.9$ \\
\hline NFI & 0.814 & 0.949 & $\geq 0.9$ \\
\hline IFI & 0.857 & 0.989 & $\geq 0.9$ \\
\hline RESEA & 0.083 & 0.026 & $<0.1$ \\
\hline
\end{tabular}

TABLE 5 EMPIRICAL TEST OF THE INFLUENCE OF GUANXI ON CIVIL SERVANT TURNOVER INTENTION AND PROMOTION OPPORTUNITIES

\begin{tabular}{|c|c|c|c|c|c|}
\hline effect & variable & Guanxi & $\begin{array}{c}\text { Promotion } \\
\text { opportunities }\end{array}$ & $\begin{array}{c}\text { Job } \\
\text { Satisfaction }\end{array}$ & $\begin{array}{l}\text { turnover } \\
\text { intention }\end{array}$ \\
\hline Guanxi & $\begin{array}{c}\text { Total effect } \\
\text { Direct effect } \\
\text { Indirect effect }\end{array}$ & - & $\begin{array}{l}-0.284 * * * \\
-0.088 \\
-0.196 * * *\end{array}$ & $\begin{array}{l}-0.232 * * * \\
-0.232 * * * \\
-\end{array}$ & $\begin{array}{l}0.507 * * * \\
0.368 * * * \\
0.140 * * *\end{array}$ \\
\hline $\begin{array}{l}\text { Promotion } \\
\text { opportuniti } \\
\text { es }\end{array}$ & $\begin{array}{c}\text { Total effect } \\
\text { Direct effect } \\
\text { Indirect effect }\end{array}$ & & & $\begin{array}{c}0.846 * * * \\
0.846 * * * \\
0.000\end{array}$ & \\
\hline $\begin{array}{c}\text { Job } \\
\text { Satisfaction }\end{array}$ & $\begin{array}{c}\text { Total effect } \\
\text { Direct effect } \\
\text { Indirect effect }\end{array}$ & & & & $\begin{array}{c}-0.604 * * * \\
-0.604 * * * \\
0.000\end{array}$ \\
\hline
\end{tabular}


From table 5, we can see that the influence of Guanxi on job satisfaction has a only direct effect. And the influence of Guanxi on turnover intention has a direct effect(0.368) more than an indirect effect(0.140), the mediation variable of job satisfaction does not work. However, the influence of Guanxi on promotion opportunities has a direct effect(-0.088) much less than an indirect effect(-0.196), the mediation variable of job satisfaction is significant.

\section{CONCLUSIONS}

Based on the above analysis, we can verify our previous research hypothesis:

H1: Guanxi directly affects turnover intention and has a significant positive effect( 0.368$)$. $\mathrm{H} 1$ is confirmed

$\mathrm{H} 2$ : Guanxi directly affect promotion opportunities and have a significant negative effect(-0.088). H2 is not confirmed.

H3: Guanxi directly affects job satisfaction and has a significant negative effect(-0.232). H3 is confirmed.

H4: Guanxi indirectly affects turnover intention through job satisfaction and has a significant positive effect(0.140). H4 is confirmed.

H5:Guanxi indirectly affects promotion opportunities through job satisfaction and has a significant negative effect(-0.196). H5 is confirmed.

Based on a series of analyses of the Guanxi's model of civil servant turnover intention and promotion opportunities, we can see that Guanxi is an informal negative relationship in the civil service organization system and has a significant negative effect on the development of the civil service organization. The existence of stronger Guanxi in the organization will not only reduce the job satisfaction of civil servants, but also increase civil servants' willingness to leave. This has an unfavorable influence on the development of civil service organizations, the introduction of talents, fair and reasonable and healthy organizational atmosphere. It is extremely likely to cause cronyism within the organization and undermine the organization's fairness and employee satisfaction. Therefore, it is necessary to strengthen the construction of related systems and regulations, and to promote the promotion mode based on performance evaluation and capacity, and actively promote the construction of a contractual and equal-type Guanxi.

\section{ACKNOWLEDGEMENTS}

This study is funded by Chinese national social science fund :"Empirical Study on Resignation Behaviors of Civil Servants"(14BZZ055). And "Talent Introduction" program of Yunnan University of Finance and Economics: "Study on Issues of Civil Servants Resignation and Countermeasures--Take Yunnan Province as an example".

\section{REFERENCES}

[1] Cai Xunguang. Contemporary Chinese Social Interpersonal Relationship from the Perspective of Social Exchange Theory[M]. Theoretical Review, 2008(3). P52-P53. (In Chinese)

[2] Bao Gongmin, Liu Ye. A Review of the Study of Relationship Theory [J]Technology and Economy, No. 4, 2008. P109-P115. (In Chinese)

[3] Zhang Zhe. Research and application of the employee intention to leave the company[M]. Beijing: Tsinghua University Press, 2006.P74. (In Chinese)

[4] Cheung,MillissaF.Y.,Wu,Wei-Ping,Chan,AllanK.K.,Wong, MayM.L. Supervisor-Subordinator Guanxi and Employee Work Outcomes:The mediating Role of Job Satisfaction[J]. Journal of Business Ethics, 2009.P77-89.

[5] Chen ,Chao C., Chen ,Ya-Ru, Xin, Katherine. Guanxi Practices and Trust in Management--AProceduralJusticePerspective[J]. Organization Science, 2016(2).P200-P209.

[6] Li JJ. Effects of fair performance and guanxi operations on job satisfaction and organizational citizenship behaviors and the mediating effect of assessment of acceptance, ambition, and guanxi epidemic - based on the research of state-owned enterprises[M]. Journal of Renmin University of China 2013.P24- 28. (In Chinese)

[7] Chen, Ying, Friedman, Ray\& Yu, ,Enhai and Sun ,Fubin. Examining the positive and negative effects of guanxi practices: A Multi-level analysis of guanxi practices and procedural justice perceptions[J]. Asia Pac J Manag,2011.P715-733.

[8] Yong-Kang LI. Analysis of Resignation Trend of Chinese Civil Servants[J].SEME(2016),P4.

[9] Ren Yinghua. Statistical model of modern service industry agglomeration and its application[M]. Hunan University Press, 2011.P12. (In Chinese)

[10] Xu Sumin."City People Cultivate Wisdom and Cleverness, and Yu Ruo Ruo Tong Meng" A Comparative Study of Russell's Chinese and Western Philosophies[J].Academic Research,2013(9).P1-3.(In Chinese)

[11] Jingmen City Museum. Guodian Chu Tomb Bamboo Slips[M]. Beijing: Cultural Relics Publishing House, 1998.P157. (In Chinese)

[12] Ge Yun.Innovation of Institutional Innovation or Idea Updating: An Administrative Cultural Consideration in Improving People's Livelihood in Social Transition Period[J].Social Sciences Research,2012,1.P56-61. (In Chinese)

[13] Li Peilin. "Another Invisible Hand": Social Structure Transformation, Development Strategy, and Organizational Innovation[M]. Beijing: China Society Press, 1998.P35-40. (In Chinese)

[14] Song Linfei. Western sociological theory [M]. Nanjing: Nanjing University Press, 1997. P510-514. (In Chinese)

[15] Chen Yunliang.Confucian ethics and the spirit of the rule of law[J].Chinese Journal of Law,2000(5).P11-20. (In Chinese)

[16 ]Wang Ying,Wang Xiaoyu.Study on the Staying Motivation of Chinese Civil Servants' Workplace:Professional Commitment and Its Influencing Factors[J].China Administration 2016(5).P20-24. (In Chinese) 